\title{
Neurocognitive impairment and evidence-based treatment options in Bipolar disorder
}

\author{
Konstantinos N. Fountoulakis ${ }^{*}$ (1)
}

\begin{abstract}
Background: The current paper briefly summarizes the literature on the neurocognitive deficit and its treatment in BD patients.

Methods: The material was chosen on the basis of previous systematic reviews the author has taken part in.

Results: The data so far suggest that the deficit is qualitatively similar but quantitatively milder in comparison to schizophrenia, it is present already since the first episode, is weakly related to mood symptoms and somewhat stronger to psychotic symptoms, it probably determines much of the disability and treatment is problematic. This deficit is also present during periods of euthymia. The possible adverse effect of psychotropic medication is rather small if any at all and is confounded by the specific clinical symptoms, for which medication is used for their treatment. This is especially true concerning antipsychotics and psychotic symptoms. The origin and the etiopathogenesis of the core neurocognitive impairment remain elusive. The presence of a neurodegenerative and of a neurodevelopmental component has both data in favor and against and they are both the focus of debate.
\end{abstract}

Conclusions: Treatment of the neurocognitive deficit and restoration of functioning is problematic. The data are limited and treatment options are few and with a weak overall effect. Pharmacological treatments, ECT and rTMS present some hard data, while the literature is inconclusive concerning psychotherapeutic interventions.

Keywords: Bipolar disorder, Neurocognitive disorder, Cognitive disorder, Cognitive remediation, Functional remediation, treatment

\section{Background}

The nature of the neurocognitive dysfunction in mood disorders, and particularly in Bipolar disorder (BD), has been the focus of debate for long and only during the last couple of decades the picture became clearer. It seems that the neurocognitive deficit is not only an enduring component of $\mathrm{BD}$, but also represents a core primary characteristic, rather than being secondary to the mood state or medication. A number of other questions are also

*Correspondence: kfount@med.auth.gr

3rd Department of Psychiatry, School of Medicine, Aristotle University of Thessaloniki, 6, Odysseos str (1st Parodos Ampelonon str.), Pylaia,

55535 Thessaloniki, Greece important, that is whether it is the result of a neurodevelopmental or neurodegenerative process and what is its relationship to the widely believed higher creativity of $\mathrm{BD}$ patients.

Today, there is a number of studies suggesting that almost half of BD patients are impaired in one neurocognitive domain, one-third or more are impaired in at least two neurocognitive domains and more than one-fifth in three or more domains $[1,2]$. This deficit is rather stable and relatively independent from mood changes, probably reflecting trait features [3-6] Importantly, even after controlling for confounding variables, like education and social class and clinical symptoms, the neurocognitive 
impairment in $\mathrm{BD}$ is less pronounced in comparison to that in schizophrenia $[7,8]$.

A significant limitation in the literature is that the performance in most tests is influenced by more than one neurocognitive process. This is not a technical problem; it rather reflects the fact that the boundaries between neurocognitive processes are unclear and no process is completely independent from the others. As a consequence, different approaches in their classification and nomenclature have been proposed, adding to the confusion. In Table 1, a list of neurocognitive functions together with the tools used in their assessment are presented.

The current paper is a narrative review and reflects the opinion of the author on the issue of the neurocognitive deficit in BD and its treatment options. It is not a systematic review by itself but it is based on the systematic examination of data by the author as this has been published in the past $[9,10]$. Essentially it is a selective review updated to date. In this frame, the references included in this paper are also selected as being the most important and thus, the list of references is not exhausted. As the aim was to produce a small comprehensive text, many definitions were omitted and much fundamental knowledge on BD and neurocognition are considered already mastered by the reader.

\section{General neurocognitive functioning and intelligence quotient (IQ)}

The literature suggests that both BD patients and their families have above average IQ and general intellectual functioning [11], or at least they have intelligence similar to healthy controls [12-16].

However, it also suggests that there is a moderate global reduction in comparison to their premorbid state in their neurocognitive functioning as reflected in their IQ scores and their performance in neuropsychological batteries, irrespective of illness phase [17-21].

According to a meta-analysis, patients with BD, show higher Verbal IQ in comparison to Performance IQ scores $[22,23]$. The VIQ-PIQ discrepancy might reflect

Table 1 Neurocognitive domains assessed in the literature and neuropsychological tools used

\begin{tabular}{|c|c|}
\hline Domain & Tool \\
\hline Premorbid IQ & $\begin{array}{l}\text { Single-word reading score from the North American Adult Reading Test } \\
\text { (NAARTWide Range Achievement Test (WRAT) } \\
\text { Vocabulary subtest score from the Wechsler Adult Intelligence Scale (WAIS) }\end{array}$ \\
\hline Current IQ & Wechsler Adult Intelligence Scale (WAIS) \\
\hline Psychomotor and mental speed & $\begin{array}{l}\text { Digit Symbol Substitution Test (DSST) } \\
\text { Trail Making Test-A (TMT-A) } \\
\text { Reaction time tests }\end{array}$ \\
\hline Attention & $\begin{array}{l}\text { Continuous Performance Test (CPT) } \\
\text { Digits Forward }\end{array}$ \\
\hline Working memory & Digits Backward \\
\hline \multicolumn{2}{|l|}{ Verbal memory } \\
\hline Learning & California Verbal Learning Test (CVLT) \\
\hline Short delayed recall & Rey Auditory Verbal Learning Test (RAVLT) \\
\hline Long delayed recall & Wechsler Memory Scale-Logical Memory (WMS-LM) \\
\hline Recognition & Free recall \\
\hline Nonverbal memory & $\begin{array}{l}\text { Rey Complex Figure Test (RCFT)_Immediate and delayed recall } \\
\text { Wechsler Memory Scale-Visual Reproduction (WMS-VR) }\end{array}$ \\
\hline Visuospatial function & $\begin{array}{l}\text { Block design } \\
\text { Rey Complex Figure Test (RCFT)-copy }\end{array}$ \\
\hline Language/verbal fluency & $\begin{array}{l}\text { Controlled Oral Word Association Test (COWA-FAS) } \\
\text { Animal Naming (AN) }\end{array}$ \\
\hline Executive function & $\begin{array}{l}\text { Wisconsin Card Sorting Test (WCST)_Categories achieved and perseverative errors } \\
\text { Stroop Color Word Test (SCWT) } \\
\text { Trail Making Test-B (TMT-B) }\end{array}$ \\
\hline Social cognition and theory of mind & $\begin{array}{l}\text { Benton Facial Recognition Test (BFRT) } \\
\text { Faces Test (FT) } \\
\text { Eyes Test }(\mathrm{ET}) \\
\text { Hinting Task }(\mathrm{HT}) \\
\text { False belief and deception tasks } \\
\text { Picture sequencing } \\
\text { Character intention tasks } \\
\text { Faux Pas }\end{array}$ \\
\hline
\end{tabular}


a specific effect of BD on 'fluid intelligence' (the capacity to think logically and solve problems in novel situations, independently of acquired knowledge) with a simultaneous respect of the 'crystallized intelligence' (the ability to use skills, knowledge, and experience; it does rely on long-term memory) [24].

When all phases of the illness are taken into consideration, the effect sizes concerning current IQ reduction, range from 0.36 to 0.70 . For patients in remission, the results of meta-analyses are inconclusive. The effect sizes reported for PIQ range from 0.16 to 0.50 [24, 25].

\section{Psychomotor and mental speed}

Mental speed and psychomotor activation are two concepts which overlap and include reaction time, cognitive and motor speed and, manual dexterity, however, they are clearly not identical. Additionally, most of the neuropsychological tools which are used for the evaluation of psychomotor and mental speed, also assess other neurocognitive functions, and this is at least partially a consequence of a methodology effect, because in order to measure 'speed', you need to initiate a 'procedure' whose 'speed' is going to be measured.

It has been reported that the reaction time in bipolar depressive patients, is prolonged and associated with burden of illness and especially past history of depressions but not with current medication [26-30].

The deficit could be present already during the early stages of BD [31]. Individual studies, suggested that the magnitude of mental speed impairment in patients with $\mathrm{BD}$ is reported to correspond to an effect size of 0.821.08 [21, 32, 33]. When all phases of the illness are taken into consideration, the effect size $0.50-0.55$ (which is similar to that observed concerning the IQ) $[24,25]$.

\section{Attention}

Attention is a concept that includes a number of processes which work together, influence one another or prerequisite one another. These processes are: working memory (which refers to the ability to keep a limited number of mental objects in awareness for a limited duration of time), vigilance (which is the capacity to identify a specific target among many other stimuli), freedom from distraction or interference and the ability to split or to rapidly shift attention. Concentration is a term which refers to the ability to sustain attention over prolonged periods of time. There are many tests, with each of them assessing one of the previously mentioned processes. For example, the Continuous Performance Test assesses vigilance while 'span tasks' assess working memory. However, all these tests except from the specific aspect of attention they assess, are also influenced from the other processes which are related to attention as well. Working memory is often classified as belonging to the executive functions and it is often considered in relation to them.

It has been also reported that the impairment is present already during the early stages of the disorder [31]. A number of meta-analyses suggest that the effect size calculated after a meta-analysis varies between 0.41 and 0.90 depending on the sub-domain assessed [24, 34-38].

\section{Learning and memory}

Learning refers to the ability to acquire and store new information. Memory is the mental process that allows individuals to retrieve the new information at a later time. Learning and memory involve a number of processes including attention and concentration, encoding and allocation of effort. These processes are distinct from one another but interrelated and interdependent. Moreover, there are different strategies and processes involved, depending on whether a short- or a long-term effect is desirable and also depending on the quality and nature of the information and the frame it is presented in. Due to the fact that much of research on memory is focused on 'depression' and does not distinguish between unipolar and bipolar depression, the results and the conclusions from these studies should be received with reservation, because it is uncertain whether they apply specifically to $\mathrm{BD}$, and to which extend.

Deficits in all facets of memory have been reported in patients with BD [27, 28, 39-43]. It has been suggested that most memory impairments are due to the presence of confounding variables except maybe for verbal recall [44]. The same is true concerning most aspects of learning [39, 45-49].

In meta-analytic studies, when all phases of the illness are taken into consideration, the magnitude of the effect size is 0.60 for working memory, 0.43 for immediate verbal memory and 0.34 for delayed, 0.26 for immediate visual memory and 0.51 for delayed $[24,25,34,50,51]$.

\section{Verbal skills}

The evaluation of verbal skills, includes mostly the evaluation of verbal fluency. Although the literature has reported that verbal skills are impaired during all phases of $\mathrm{BD}[27,47,52]$, patients with psychotic BD manifest a worse performance with a higher effect size $(0.68-1.73)$ $[32,53,54]$. In general, when all phases of the illness are taken into consideration an effect size equal to 0.63 emerges [25]. Both letter fluency and semantic fluency are impaired during the acute manic/mixed state [34].

\section{Visuospatial skills}

Patients with BD and their unaffected relatives show impairment in the visuospatial/constructional abilities [55-57] and in visual learning and memory $[57,58]$. 


\section{Executive function}

The executive system is considered to be involved in the planning, the decision-making, the error correction and the troubleshooting, in situations where responses are not well-rehearsed or contain novel sequences of actions, are dangerous or constitute technically difficult situations or situations requiring the overcoming of a strong habitual response or resisting temptation. In other words, 'Controlling of mental and neurocognitive processes' seems to be the key phrase describing the role of executive functions. In patients with $\mathrm{BD}$, reasoning should be considered separately from the rest executive functions due to the fact that it seems to rely heavily on verbal and linguistic skills [24].

A severe impairment in executive functions except reasoning during all phases of BD is generally reported [28, 59-61] and it might be particularly severe concerning interference and inhibitory control [62-65].

Meta-analyses suggested that when taking all phases of the illness together, the effect size of this impairment is equal to $0.34-0.99$ depending on the aspect of the cognitive function under investigation and the phase of the illness $[24,25,34,37,38,66,67]$.

\section{Social cognition and theory of mind (ToM)}

The term 'Social cognition' constitutes a psychological domain with several dimensions. It refers not only to the ability of the person to assume that other people have minds similar to his/her own and to interpret, but also to understand and predict the emotions, desires, intentions, behaviors and speech of others (including nonverbal elements). Social cognition shapes communication and interaction with others and in this way enabling adaptive social adaptation. It involves a complex set of processes including the representation of internal somatic states, knowledge about the self, perception of others, and interpersonal motivations.

The broad Theory of mind (ToM), includes three main processes (a narrow definition of ToM, emotion processing, and affective decision-making). The narrow definition of ToM (mentalizing or mindreading), refers to the ability to attribute mental states (e.g. beliefs, desires, and intents) to oneself and to others. Emotion processing is the ability to identify and discriminate basic emotions. Affective decision-making is crucial for an appropriate social behavior, and concerns weighing up choices in association with reward and punishment.

The tests which are used to evaluate these domains are both verbal (scenarios) and nonverbal (pictures). They demand the subject to identify and comprehend the situation, the roles and the interactions and to make appropriate planning. So far, empirical data have confirmed the universality of facial emotions. This means that the specific ability to process and identify facial emotions is a substantial feature of human communication and social interaction, which is independent of culture.

Generally, the literature supports the presence of a robust deficit in ToM in BD patients [68-75]. This deficit seems restricted to the acute phases of the illness even when memory was controlled for [39] and thus there is no impairment during remission [76].

There are inconclusive data concerning the recognition of emotions in BD patients, and there is little or no difference between patients with $\mathrm{BD}$ and controls on the emotional decision-making component [10, 77, 78].

An effect size concerning ToM equal to $0.75-0.86$ and concerning emotion processing equal to 0.35 was reported [79].

\section{Clinical correlations}

Medication constitutes an important confounding variable when comparing the different phases of BD. Some acutely ill patients might be medication-free during testing, however, this is not the case with patients in remission. As a result, medication status not only constitutes a confounding variable which is difficult to control for, but also might introduce a bias towards the detection of a deficit, especially in patients in remission. On the other hand, however, patients with severe mania or severe depression cannot be tested and are rarely off medication. Medication could be a possible reason why patients with $\mathrm{BD}$ have poor performance on certain neurocognitive tasks. This is in accord with the traditional concept that $\mathrm{BD}$ is considered to belong to the 'functional psychoses. According to this approach, the attentional impairment is considered to be the core neurocognitive deficit and the cause of all other deficits in neurocognition.

Patients under lithium often report that lithium inhibits their productivity and creativity [80]. Additionally, it seems that lithium has a negative impact on neurocognition especially on memory and psychomotor functioning $[81,82]$. Lithium also causes a deficit in the long-term recall (retrieval) without having an effect on attention or on encoding. This impairment might especially concern verbal memory [32, 83].

The data on the possible deleterious effect of antipsychotics and antiepileptics on neurocognition are rare and conflicting [84-86]. Even after controlling for clinical features, current antipsychotic treatment is related to worse performance across all executive function tests as well as in verbal learning and recognition memory and in semantic fluency in BD patients [50,87, 88].

Overall, it has been shown that medications have a limited adverse effect on neurocognitive function [89] if any at all [90-92]. 
It has been shown that both the presence of psychotic symptoms [93-97] as well as the history of psychotic features are also strongly related to a worse neurocognitive performance [94, 98, 99].

It is interesting that the neurocognitive impairment is present during all phases of $\mathrm{BD}$. A meta-analysis, calculated the respected effect sizes for specific neurocognitive domains separately for each phase. During the acute manic/mixed states, these effect sizes showed a clear impairment in attention (0.79-0.90), verbal learning (1.43) and delayed free verbal recall (1.05), letter fluency (0.51) and semantic fluency (0.59), general executive function (0.72) and speeded set-shifting (0.64). During acute bipolar depression, there were impairments in attention (0.80), verbal memory (1.20), phonemic fluency (0.93) and executive function in speeded set-shifting (0.64). During the euthymic phase, these effect sizes showed a clear impairment in auditory (0.41) and sustained visual vigilance $(0.69)$ and speeded visual scanning $(0.65)$, working memory $(0.65)$, verbal learning $(0.81)$ and long-delay verbal free recall (0.78), executive functions concerning problem-solving tasks (0.54), verbal interference (0.75) and set-switching tasks (0.73), immediate nonverbal memory (0.73), delayed nonverbal recall (0.80), visuospatial function (0.55), phonemic (0.51), and semantic $(0.75)$ verbal fluency and finally in psychomotor speed (0.66) [34]. Overall, these results suggested that patients in a manic or depressed state had significantly greater effect size impairment in verbal learning than patients in an euthymic state.

Important is to note that the overall evidence suggests that the observed neurocognitive deficit in BD patients is not secondary and does not constitute a by-product of mood symptomatology or of exposure to medication. This is in spite of the observed strong relationship between mood symptoms and neurocognitive impairment. The most probable explanation is that neurocognitive impairment reflects a deeper neurobiological dysfunction which probably includes the presence of premorbid developmental abnormalities [100].

Although the prevailing opinion is that BD-II patients perform better than BD-I but worse than healthy controls the literature has shown that in quantitative terms, BD-II does not differ much from BD-I [101-104].

\section{Long-term development of the neurocognitive deficit}

According to Kraepelin, BD was originally considered to be an episodic illness with a rather benign course and outcome, but this is no longer the case.

The overall longitudinal course suggests that neurodevelopmental factors play a minor role in the emergence of neuropsychological dysfunction in $\mathrm{BD}[100,105]$ but opposite findings do exist [106]. Recent findings suggest that its course is often characterized by chronicity and residual symptoms with lack of remission between episodes, and possibly there is a progressive neurocognitive deficit. In this frame, an important role is attributed to the neurocognitive impairment in the specific clinical course of BD [107, 108]. As previously mentioned, there is a deleterious effect of psychotic symptoms [105] but otherwise the data in favor of a neurodegeneration are not consistent, and this is why the progression is characterized as 'possible' $[109,110]$. It seems that eventually $\mathrm{BD}$ patients come to manifest a neurocognitive deficit similar in qualitative as well as in quantitative terms to patients with schizophrenia (Fig. 1).

The neurocognitive deficit is largely responsible for functional disability [111] and it is important to note that objective and not perceived deficit is what correlates with disability [112].

A graphical representation of the long-term development of the neurocognitive deficit in BD patients in comparison to schizophrenia and normal controls is shown in Fig. 1.

\section{Awareness of the neurocognitive deficit}

Although many patients with BD complain frequently about neurocognitive problems in attention, concentration and memory, there are limited data on the relationship between subjective cognitive complaints with objective neuropsychological deficits.

The patients' subjective cognitive complaints do not seem to correlate or predict objective neuropsychological deficits [113-115] or disability [112]. There are some possibility mood symptoms to mediate lack of awareness but currently, this is a matter of debate [116].

\section{Treatment of the neurocognitive deficit}

It is important to assess the patient in a precise way and locate the areas of neurocognitive impairment so that monitoring of response is possible. Even patients in full remission should be assessed in detail [117].

There some but limited hard data concerning the efficacy of psychopharmacological agents in the treatment of neurocognitive deficit $[118,119]$. The literature suggests that galantamine may have specific benefits for episodic memory, but not processing speed, in patients with cognitive impairment as part of BD [120]. Pramipexole may improve neurocognition in euthymic patients only [121], while the data are negative for $\mathrm{N}$-acetyl cysteine (NAC) [122]. Adjunctive intranasal insulin (40 IU q.i.d.; $\mathrm{N}=34$ ) had a beneficial effect on executive function but not on the other neurocognitive measures in euthymic patients [123]. Also adjunctive mifepristone, which is a synthetic steroid, at $600 \mathrm{mg} /$ day improved spatial working 


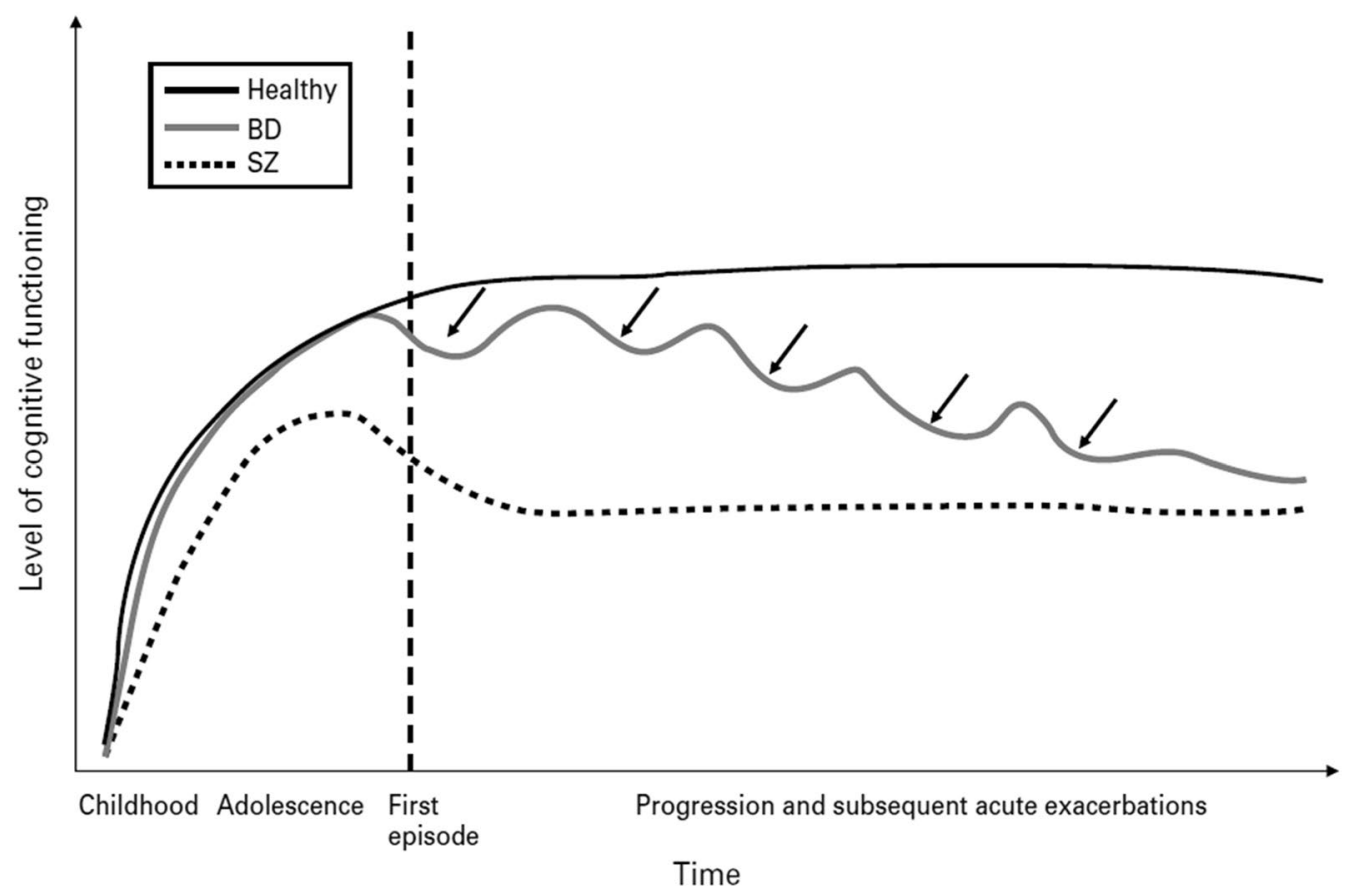

Fig. 1 Long-term evolution of the neurocognitive deficit in BD patients, in comparison to patients with schizophrenia and normal subjects. Overall, in contrast to schizophrenia patients, BD patients exhibit a relatively intact cognitive functioning throughout childhood and adolescence, and the neurocognitive deterioration is observed only after the overt symptom onset (Reproduced after permission from Lewandowski et al. [105])

memory in BD depressed patients, and this was evident also 7 weeks after the cessation of treatment [124]. A randomized, open-label, pilot study, on euthymic BD-I patients supported the use of adjunctive lurasidone adjunctive in improving cognition [125]. A more recent study reported that six intravenous infusions of ketamine $(0.5 \mathrm{mg} / \mathrm{kg})$ over a 12 -day period improved the speed of processing and verbal learning but it seemed that the improvement in depression mediated these results, with better baseline neurocognitive function being predictive of a better outcome [126].

There are also some limited data in support of the usefulness of non-pharmacological biological treatments. ECT was reported to produce an improvement in neurocognitive function similar to that of algorithmbased pharmacological treatment [127]. A recent study reported that ten consecutive days of high-frequency active rTMS improved aspects of neurocognition without an effect on mood symptoms [128].

Concerning psychotherapies, the most often used methods are Cognitive Remediation and Functional Remediation. Overall, the data are positive in improving functioning, which is the critical endpoint, but mostly negative concerning cognitive outcomes when using cognitive remediation techniques as add on to
TAU in BD patients [129-132], although a more recent post hoc analysis was promising [133].

A recent systematic review identified eleven articles reporting data on Cognitive and Functional Remediation from seven original studies encompassing 471 participants. These authors concluded that methodological quality was problematic and there was a moderate risk of bias. While the majority of studies reported a beneficial effect, the findings were isolated and not replicated across studies, making any conclusions problematic [134].

A recent study reported that Functional Remediation had no effect in serum brain derived neurotrophic factor (BDNF) levels in euthymic adult BD patients despite the improvement in psychosocial functioning [135].

\section{Discussion}

The current paper briefly summarized the view of the author concerning the literature on the neurocognitive deficit and its treatment in $\mathrm{BD}$ patients $[9,10]$. The area is understudied, but the data so far suggest that neurocognition in BD is an important issue, the deficit is qualitatively similar but quantitatively milder in comparison to schizophrenia, it is present already since the first episode, is weakly related to mood symptoms and somewhat stronger to psychosis, it probably determines much of 
the disability associated with $\mathrm{BD}$ and treatment is problematic. This deficit is also present during periods of euthymia and the possible adverse effect of psychotropic medication is rather small if any at all and is confounded by the specific clinical symptoms, for which medication is used for their treatment. This is especially true concerning antipsychotics and psychotic symptoms.

The core deficit, which constitutes a direct consequence of the disease itself, seems to be relatively (but not completely) independent not only from the other components of the disease but also from mood symptoms. This core deficit is either increased or on the contrary it is attenuated by many factors like the disease phase, specific personal characteristics of the patients (age, gender, education, etc.), current symptomatology and its treatment and the long-term course and the long-term exposure to medication, psychiatric and somatic comorbidity and alcohol and/or substance abuse.

However, the origin and the etiopathogenesis of the core neurocognitive impairment remain elusive. The presence of a neurodegenerative component as a consequence of repeated mood episodes and psychotic features and of a neurodevelopmental component has both data in favor and against and they are both the focus of debate. This probably differentiates BD from schizophrenia, in which the neurodevelopmental component is strong. Such a neurodevelopmental effect is evident in some but not all patients with BD.

Overall, the neurocognitive deficit concerns almost all domains with only a few exceptions and its magnitude is at the severe range during the acute episodes and at the medium range during euthymia. A summary of effect sizes by neurocognitive domain and illness phase is shown in Table $2[9,10]$.

The specific clinical course of the illness seems to play an important role. A course characterized by residual symptoms, chronicity and lack of remission between episodes is related to a progressive neurocognitive deficit. Of significant importance is the adverse effect specifically of psychotic symptoms, while manic episodes seem to affect neurocognitive function more than depressive episodes do. Age, age at onset, duration of the illness and number of episodes, not only reflect distinct but overlapping aspects of the overall disease burden but also are related to the neurocognitive impairment and its progression.

Table 2 Effect sizes concerning the various neurocognitive domains during different phases of BD as well as in high risk relatives (endophenotypes)

\begin{tabular}{|c|c|c|c|c|c|}
\hline Domain & All phases & Acute mania & $\begin{array}{l}\text { Acute bipolar } \\
\text { depression }\end{array}$ & Euthymia & Endophenotypes \\
\hline \multicolumn{6}{|l|}{ Intelligence Quotient (IQ) } \\
\hline Premorbid IQ & Normal & & & & Normal \\
\hline Current IQ & $0.36-0.70$ & $0.28-0.47$ & & $0.11-0.50$ & 0.20 \\
\hline Psychomotor and mental speed & $0.50-0.55$ & & & $0.52-0.80$ & $0.17-0.22$ \\
\hline Attention & 0.64 & $0.79-0.90$ & 0.80 & $0.41-0.80$ & $0.18-0.36$ \\
\hline \multicolumn{6}{|l|}{ Memory } \\
\hline Working memory & 0.60 & & & $0.54-1.02$ & \\
\hline \multicolumn{6}{|l|}{ Verbal memory } \\
\hline Immediate & 0.43 & & & $0.73-0.82$ & $0.33-0.42$ \\
\hline Delayed & 0.34 & 1.05 & 1.20 & $0.71-0.85$ & $0.27-0.33$ \\
\hline Verbal learning & 0.91 & 1.43 & & $0.66-0.90$ & 0.28 \\
\hline \multicolumn{6}{|l|}{ Nonverbal memory } \\
\hline Immediate & 0.26 & & & 0.73 & \\
\hline Delayed & 0.51 & & & $0.62-0.80$ & 0.13 \\
\hline Episodic memory & & & & 0.62 & \\
\hline Visuospatial function & 0.65 & & & $0.22-0.57$ & \\
\hline Language/verbal fluency & 0.63 & $0.51-0.59$ & 0.93 & $0.34-0.90$ & 0.27 \\
\hline Executive function & $0.34-0.79$ & $0.64-0.72$ & $0.54-0.75$ & $0.52-0.88$ & $0.24-0.51$ \\
\hline \multicolumn{6}{|l|}{ Social cognition } \\
\hline ToM & $0.75-0.86$ & & & & \\
\hline Emotion recognition & 0.35 & & & & \\
\hline Emotion decision-making & Normal & & & & \\
\hline
\end{tabular}

The range of values reflects heterogeneity in study samples but also heterogeneity because of the different neuropsychological tools used 
However, the data are inconclusive concerning the magnitude and the true nature of this relationship.

\section{Conclusion}

The neurocognitive deficit in $\mathrm{BD}$ is relatively (but not completely) independent not only from the other components of the disease but also from mood symptoms. Its treatment and the restoration of functioning are problematic. Not only the data are limited but it seems that treatment options are few and with a weak overall effect. Pharmacological treatments, ECT and rTMS present some hard data, while the literature is inconclusive concerning psychotherapeutic interventions.

\section{Authors' contributions}

The author searched the literature, wrote and corrected the manuscript. The author read and approved the final manuscript.

\section{Funding}

None.

\section{Availability of data and materials}

Not applicable.

\section{Consent for publication}

Not applicable.

\section{Competing interests}

KNF has received grants and served as consultant, advisor or CME speaker for the following entities: AstraZeneca, Bristol-Myers Squibb, Eli Lilly, Ferrer, Gedeon Richter, Janssen, Lundbeck, Otsuka, Pfizer, the Pfizer Foundation, Sanofi-Aventis, Servier, Shire and others.

Received: 10 May 2020 Accepted: 17 September 2020

Published online: 23 September 2020

\section{References}

1. Gualtieri CT, Morgan DW. The frequency of cognitive impairment in patients with anxiety, depression, and bipolar disorder: an unaccounted source of variance in clinical trials. J Clin Psychiatry. 2008;69(7):1122-30.

2. Martino DJ, Strejilevich SA, Scapola M, Igoa A, Marengo E, Ais ED, Perinot L. Heterogeneity in cognitive functioning among patients with bipolar disorder. J Affect Disord. 2008;109(1-2):149-56.

3. Clark L, Goodwin GM. State- and trait-related deficits in sustained attention in bipolar disorder. Eur Arch Psychiatry Clin Neurosci. 2004;254(2):61-8,

4. Quraishi S, Frangou S. Neuropsychology of bipolar disorder: a review. J Affect Disord. 2002;72(3):209-26.

5. Malhi GS, Ivanovski B, Szekeres V, Olley A. Bipolar disorder: it's all in your mind? The neuropsychological profile of a biological disorder. Can J Psychiat. 2004;49(12):813-9.

6. Thompson JM, Gallagher P, Hughes JH, Watson S, Gray JM, Ferrier IN Young AH. Neurocognitive impairment in euthymic patients with bipolar affective disorder. Br J Psychiatry. 2005;186:32-40.

7. Dickerson F, Boronow JJ, Stallings C, Origoni AE, Cole SK, Yolken RH. Cognitive functioning in schizophrenia and bipolar disorder: comparison of performance on the repeatable battery for the assessment of neuropsychological status. Psychiatry Res. 2004;129(1):45-53.

8. Schretlen DJ, Cascella NG, Meyer SM, Kingery LR, Testa SM, Munro CA, Pulver AE, Rivkin P, Rao VA, Diaz-Asper CM, et al. Neuropsychological functioning in bipolar disorder and schizophrenia. Biol Psychiatry. 2007;62(2):179-86.
9. Fountoulakis K. Bipolar disorder: an evidence-based guide to manic depression. Berlin: Springer-Verlag; 2015.

10. Tsitsipa E, Fountoulakis KN. The neurocognitive functioning in bipolar disorder: a systematic review of data. Ann Gen Psychiatry. 2015;14:42.

11. Koenen KC, Moffitt TE, Roberts AL, Martin LT, Kubzansky L, Harrington H, Poulton R, Caspi A. Childhood IQ and adult mental disorders: a test of the cognitive reserve hypothesis. Am J Psychiatry. 2009;166(1):50-7.

12. Gilvarry C, Takei N, Russell A, Rushe T, Hemsley D, Murray RM. Premorbid IQ in patients with functional psychosis and their first-degree relatives. Schizophr Res. 2000;41(3):417-29.

13. Zammit S, Allebeck P, David AS, Dalman C, Hemmingsson T, Lundberg I, Lewis G. A longitudinal study of premorbid IQ Score and risk of developing schizophrenia, bipolar disorder, severe depression, and other non-affective psychoses. Arch Gen Psychiatry. 2004;61(4):354-60.

14. Reichenberg A, Weiser M, Rabinowitz J, Caspi A, Schmeidler J, Mark M, Kaplan Z, Davidson M. A population-based cohort study of premorbid intellectual, language, and behavioral functioning in patients with schizophrenia, schizoaffective disorder, and nonpsychotic bipolar disorder. Am J Psychiatry. 2002;159(12):2027-35.

15. Gooding DC, Tallent KA. The association between antisaccade task and working memory task performance in schizophrenia and bipolar disorder. J Nerv Ment Dis. 2001;189(1):8-16.

16. Seidman LJ, Kremen WS, Koren D, Faraone SV, Goldstein JM, Tsuang MT. A comparative profile analysis of neuropsychological functioning in patients with schizophrenia and bipolar psychoses. Schizophr Res. 2002;53(1-2):31-44.

17. Donaldson S, Goldstein LH, Landau S, Raymont V, Frangou S. The Maudsley Bipolar Disorder Project: the effect of medication, family history, and duration of illness on IQ and memory in bipolar I disorder. J Clin Psychiatry. 2003;64(1):86-93.

18. Varga M, Magnusson A, Flekkoy K, Ronneberg U, Opjordsmoen S. Insight, symptoms and neurocognition in bipolar I patients. J Affect Disord. 2006;91(1):1-9.

19. Coffman JA, Bornstein RA, Olson SC, Schwarzkopf SB, Nasrallah HA. Cognitive impairment and cerebral structure by MRI in bipolar disorder. Biol Psychiatry. 1990;27(11):1188-96.

20. Fitzgerald D, Lucas S, Redoblado MA, Winter V, Brennan J, Anderson J, Harris A. Cognitive functioning in young people with first episode psychosis: relationship to diagnosis and clinical characteristics. Aust N Z J Psychiatry. 2004;38(7):501-10.

21. Glahn DC, Bearden CE, Barguil M, Barrett J, Reichenberg A, Bowden CL, Soares JC, Velligan DI. The neurocognitive signature of psychotic bipolar disorder. Biol Psychiatry. 2007;62(8):910-6.

22. Kluger A, Goldberg E. IQ patterns in affective disorder, lateralized and diffuse brain damage. J Clin Exp Neuropsychol. 1990;12(2):182-94.

23. McIntosh AM, Harrison LK, Forrester K, Lawrie SM, Johnstone EC. Neuropsychological impairments in people with schizophrenia or bipolar disorder and their unaffected relatives. Br J Psychiatry. 2005;186:378-85.

24. Goodwin F, Jamison K. Manic-depressive illness. 2nd ed. New York: Oxford University Press; 2007.

25. Krabbendam L, Arts B, van Os J, Aleman A. Cognitive functioning in patients with schizophrenia and bipolar disorder: a quantitative review. Schizophr Res. 2005:80(2-3):137-49.

26. MacQueen GM, Grof P, Alda M, Marriott M, Young LT, Duffy A. A pilot study of visual backward masking performance among affected versus unaffected offspring of parents with bipolar disorder. Bipolar Disord. 2004;6(5):374-8.

27. Volkert J, Kopf J, Kazmaier J, Glaser F, Zierhut KC, Schiele MA, Kittel-Schneider S, Reif A. Evidence for cognitive subgroups in bipolar disorder and the influence of subclinical depression and sleep disturbances. Eur Neuropsychopharmacol. 2015;25(2):192-202.

28. Gallagher P, Gray JM, Watson S, Young AH, Ferrier IN. Neurocognitive functioning in bipolar depression: a component structure analysis. Psychol Med. 2014:44(5):961-74.

29. Xu G, Lin K, Rao D, Dang Y, Ouyang H, Guo Y, Ma J, Chen J. Neuropsychological performance in bipolar I, bipolar II and unipolar depression patients: a longitudinal, naturalistic study. J Affect Disord. 2012;136(3):328-39.

30. Marvel CL, Paradiso S. Cognitive and neurological impairment in mood disorders. Psychiat Clin N Am. 2004;27(1):19-36. 
31. Kolur US, Reddy YC, John JP, Kandavel T, Jain S. Sustained attention and executive functions in euthymic young people with bipolar disorder. $\mathrm{Br}$ J Psychiatry. 2006;189:453-8.

32. Bora E, Vahip S, Akdeniz F, Gonul AS, Eryavuz A, Ogut M, Alkan M. The effect of previous psychotic mood episodes on cognitive impairment in euthymic bipolar patients. Bipolar Disord. 2007;9(5):468-77.

33. Basso MR, Lowery N, Ghormley C, Ward T, Purdie R, Neel J, Combs DR, Bornstein RA. Neuropsychological impairment and psychosis in mania. J Clin Exp Neuropsychol. 2009;31(5):523-32.

34. Kurtz MM, Gerraty RT. A meta-analytic investigation of neurocognitive deficits in bipolar illness: profile and effects of clinical state. Neuropsychology. 2009;23(5):551-62.

35. Robinson LJ, Thompson JM, Gallagher P, Goswami U, Young AH, Ferrier IN, Moore PB. A meta-analysis of cognitive deficits in euthymic patients with bipolar disorder. J Affect Disord. 2006;93(1-3):105-15.

36. Torres IJ, Boudreau VG, Yatham LN. Neuropsychological functioning in euthymic bipolar disorder: a meta-analysis. Acta Psychiatr Scand Suppl. 2007:434:17-26

37. Arts B, Jabben N, Krabbendam L, van Os J. Meta-analyses of cognitive functioning in euthymic bipolar patients and their first-degree relatives. Psychol Med. 2008;38(6):771-85.

38. Bora $\mathrm{E}$, Yucel $\mathrm{M}$, Pantelis $\mathrm{C}$. Cognitive impairment in affective psychoses: a meta-analysis. Schizophr Bull. 2010;36(1):112-25.

39. Ioannidi N, Konstantakopoulos G, Sakkas D, Oulis P. The relationship of Theory of Mind with symptoms and cognitive impairment in bipolar disorder: a prospective study. Psychiatriki. 2015;26(1):17-27.

40. Bourne C, Bilderbeck A, Drennan R, Atkinson L, Price J, Geddes JR, Goodwin GM. Verbal learning impairment in euthymic bipolar disorder: BDI v BDII. J Affect Disord. 2015;182:95-100.

41. Bas TO, Poyraz CA, Bas A, Poyraz BC, Tosun M. The impact of cognitive impairment, neurological soft signs and subdepressive symptoms on functional outcome in bipolar disorder. J Affect Disord. 2015;174:336-41.

42. Frydecka D, Eissa AM, Hewedi DH, Ali M, Drapala J, Misiak B, Klosinska E, Phillips JR, Moustafa AA. Impairments of working memory in schizophrenia and bipolar disorder: the effect of history of psychotic symptoms and different aspects of cognitive task demands. Front Behav Neurosci. 2014:8:416.

43. Chang JS, Choi S, Ha K, Ha TH, Cho HS, Choi JE, Cha B, Moon E. Differential pattern of semantic memory organization between bipolar I and II disorders. Prog Neuropsychopharmacol Biol Psychiatry. 2011;35(4):1053-8.

44. Malhi GS, Ivanovski B, Hadzi-Pavlovic D, Mitchell PB, Vieta E, Sachdev P. Neuropsychological deficits and functional impairment in bipolar depression, hypomania and euthymia. Bipolar Disord. 2007;9(1-2):114-25.

45. Chrobak AA, Siuda-Krzywicka K, Siwek GP, Arciszewska A, Siwek M, Starowicz-Filip A, Dudek D. Implicit motor learning in bipolar disorder. J Affect Disord. 2015;174:250-6.

46. Chakrabarty T, Kozicky JM, Torres IJ, Lam RW, Yatham LN. Verbal memory impairment in new onset bipolar disorder: relationship with frontal and medial temporal morphology. World J Biol Psychiatry. 2015;16(4):249-60.

47. Bauer IE, Keefe RS, Sanches M, Suchting R, Green CE, Soares JC. Evaluation of cognitive function in bipolar disorder using the Brief Assessment of Cognition in Affective Disorders (BAC-A). J Psychiatr Res. 2015;60:81-6.

48. Kim WJ, Ha RY, Sun JY, Ryu V, Lee SJ, Ha K, Cho HS. Autobiographical memory and its association with neuropsychological function in bipolar disorder. Compr Psychiatry. 2014;55(2):290-7.

49. Zhou JJ, Xiang YT, Wang CY, Zhou FC, Ungvari GS, Dickerson F, Chiu HF, Lai KY, Shum DH, Lee E, et al. Prospective memory deficits in euthymic bipolar disorder patients: a preliminary study. Asia-Pac Psychiatry. 2013:5(3):183-90.

50. Altshuler LL, Ventura J, van Gorp WG, Green MF, Theberge DC, Mintz J. Neurocognitive function in clinically stable men with bipolar I disorder or schizophrenia and normal control subjects. Biol Psychiatry. 2004;56(8):560-9.

51. Deckersbach T, Savage CR, Reilly-Harrington N, Clark L, Sachs G, Rauch SL. Episodic memory impairment in bipolar disorder and obsessive-compulsive disorder: the role of memory strategies. Bipolar Disord. 2004;6(3):233-44.

52. Sung K, Gordon B, Vannorsdall TD, Ledoux K, Schretlen DJ. Impaired retrieval of semantic information in bipolar disorder: a clustering analysis of category-fluency productions. J Abnorm Psychol. 2013;122(3):624-34.

53. Gruzelier J, Seymour K, Wilson L, Jolley A, Hirsch S. Impairments on neuropsychologic tests of temporohippocampal and frontohippocampal functions and word fluency in remitting schizophrenia and affective disorders. Arch Gen Psychiatry. 1988;45(7):623-9.

54. Selva G, Salazar J, Balanza-Martinez V, Martinez-Aran A, Rubio C, Daban C, Sanchez-Moreno J, Vieta E, Tabares-Seisdedos R. Bipolar I patients with and without a history of psychotic symptoms: do they differ in their cognitive functioning? J Psychiatr Res. 2007:41(3-4):265-72.

55. Dittmann S, Seemuller F, Grunze HC, Schwarz MJ, Zach J, Fast K, Born C, Dargel S, Engel RR, Bernhard B, et al. The impact of homocysteine levels on cognition in euthymic bipolar patients: a cross-sectional study. J Clin Psychiatry. 2008;69(6):899-906.

56. Atre-Vaidya N, Taylor MA, Seidenberg M, Reed R, Perrine A, GlickOberwise F. Cognitive deficits, psychopathology, and psychosocial functioning in bipolar mood disorder. Neuropsychiatry Neuropsychol Behav Neurol. 1998;11(3):120-6.

57. Sapin LR, Berrettini WH, Nurnberger JI Jr, Rothblat LA. Mediational factors underlying cognitive changes and laterality in affective illness. Biol Psychiatry. 1987;22(8):979-86.

58. Ferrier IN, Stanton BR, Kelly TP, Scott J. Neuropsychological function in euthymic patients with bipolar disorder. Br J Psychiatry. 1999;175:246-51.

59. David DP, Soeiro-de-Souza MG, Moreno RA, Bio DS. Facial emotion recognition and its correlation with executive functions in bipolar I patients and healthy controls. J Affect Disord. 2014;152-154:288-94.

60. Torralva T, Strejilevich S, Gleichgerrcht E, Roca M, Martino D, Cetkovich M, Manes F. Deficits in tasks of executive functioning that mimic real-life scenarios in bipolar disorder. Bipolar Disord. 2012;14(1):118-25

61. Wolf F, Brune M, Assion HJ. Theory of mind and neurocognitive functioning in patients with bipolar disorder. Bipolar Disord. 2010;12(6):657-66.

62. Barbosa IG, Rocha NP, Huguet RB, Ferreira RA, Salgado JV, Carvalho LA, Pariante CM, Teixeira AL. Executive dysfunction in euthymic bipolar disorder patients and its association with plasma biomarkers. J Affect Disord. 2012;137(1-3):151-5.

63. Larson ER, Shear PK, Krikorian R, Welge J, Strakowski SM. Working memory and inhibitory control among manic and euthymic patients with bipolar disorder. J Int Neuropsychol Soc. 2005;11(2):163-72.

64. Yechiam E, Hayden EP, Bodkins M, O'Donnell BF, Hetrick WP. Decision making in bipolar disorder: a cognitive modeling approach. Psychiatry Res. 2008;161(2):142-52.

65. Chandler RA, Wakeley J, Goodwin GM, Rogers RD. Altered riskaversion and risk-seeking behavior in bipolar disorder. Biol Psychiatry. 2009;66(9):840-6.

66. Mann-Wrobel MC, Carreno JT, Dickinson D. Meta-analysis of neuropsychological functioning in euthymic bipolar disorder: an update and investigation of moderator variables. Bipolar Disord. 2011;13(4):334-42.

67. Bora E, Yucel M, Pantelis C. Cognitive endophenotypes of bipolar disorder: a meta-analysis of neuropsychological deficits in euthymic patients and their first-degree relatives. J Affect Disord. 2009;113(1-2):1-20.

68. Bora $\mathrm{E}$, Yucel M, Pantelis C. Theory of mind impairment: a distinct traitmarker for schizophrenia spectrum disorders and bipolar disorder? Acta Psychiatr Scand. 2009;120(4):253-64.

69. Montag C, Ehrlich A, Neuhaus K, Dziobek I, Heekeren HR, Heinz A, Gallinat J. Theory of mind impairments in euthymic bipolar patients. J Affect Disord. 2010;123(1-3):264-9.

70. Shamay-Tsoory S, Harari H, Szepsenwol O, Levkovitz Y. Neuropsychological evidence of impaired cognitive empathy in euthymic bipolar disorder. J Neuropsychiatry Clin Neurosci. 2009;21(1):59-67.

71. Adida M, Jollant F, Clark L, Besnier N, Guillaume S, Kaladjian A, MazzolaPomietto P, Jeanningros R, Goodwin GM, Azorin JM, et al. Trait-related decision-making impairment in the three phases of bipolar disorder. Biol Psychiatry. 2011;70(4):357-65. 
72. Lahera G, Ruiz-Murugarren S, Iglesias P, Ruiz-Bennasar C, Herreria E, Montes JM, Fernandez-Liria A. Social cognition and global functioning in bipolar disorder. J Nerv Ment Dis. 2012;200(2):135-41.

73. Olley AL, Malhi GS, Bachelor J, Cahill CM, Mitchell PB, Berk M. Executive functioning and theory of mind in euthymic bipolar disorder. Bipolar Disord. 2005;7(Suppl 5):43-52.

74. Inoue $Y$, Tonooka $Y$, Yamada $K$, Kanba S. Deficiency of theory of mind in patients with remitted mood disorder. J Affect Disord. 2004;82(3):403-9.

75. Bonshtein $\mathrm{U}$, Leiser $\mathrm{D}$, Levine J. Naive theory impairment in schizophrenia: is it domain-specific? J Nerv Ment Dis. 2006;194(10):753-9.

76. Kerr N, Dunbar RI, Bentall RP. Theory of mind deficits in bipolar affective disorder. J Affect Disord. 2003;73(3):253-9.

77. Addington J, Addington D. Facial affect recognition and information processing in schizophrenia and bipolar disorder. Schizophr Res. 1998;32(3):171-81.

78. Lior R, Nachson I. Impairments in judgment of chimeric faces by schizophrenic and affective patients. Int J Neurosci. 1999;97(3-4):185-209.

79. Samame C, Martino DJ, Strejilevich SA. Social cognition in euthymic bipolar disorder: systematic review and meta-analytic approach. Acta Psychiatr Scand. 2012;125(4):266-80.

80. Shaw ED, Mann JJ, Stokes PE, Manevitz AZ. Effects of lithium carbonate on associative productivity and idiosyncrasy in bipolar outpatients. Am J Psychiatry. 1986;143(9):1166-9.

81. Honig A, Arts BM, Ponds RW, Riedel WJ. Lithium induced cognitive side-effects in bipolar disorder: a qualitative analysis and implications for daily practice. Int Clin Psychopharmacol. 1999;14(3):167-71.

82. Kessing LV. Cognitive impairment in the euthymic phase of affective disorder. Psychol Med. 1998;28(5):1027-38.

83. Senturk V, Goker C, Bilgic A, Olmez S, Tugcu H, Oncu B, Atbasoglu EC. Impaired verbal memory and otherwise spared cognition in remitted bipolar patients on monotherapy with lithium or valproate. Bipolar Disord. 2007;9(Suppl 1):136-44.

84. Holmes MK, Erickson K, Luckenbaugh DA, Drevets WC, Bain EE, Cannon DM, Snow J, Sahakian BJ, Manji HK, Zarate CA Jr. A comparison of cognitive functioning in medicated and unmedicated subjects with bipolar depression. Bipolar Disord. 2008;10(7):806-15.

85. Pan YJ, Hsieh MH, Liu SK. Visuospatial working memory deficits in remitted patients with bipolar disorder: susceptibility to the effects of GABAergic agonists. Bipolar Disord. 2011;13(4):365-76.

86. Goldberg JF, Chengappa KN. Identifying and treating cognitive impairment in bipolar disorder. Bipolar Disord. 2009;11 (Suppl 2):123-37.

87. Frangou S, Donaldson S, Hadjulis M, Landau S, Goldstein LH. The Maudsley Bipolar Disorder Project: executive dysfunction in bipolar disorder I and its clinical correlates. Biol Psychiatry. 2005;58(11):859-64.

88. Jamrozinski K, Gruber O, Kemmer C, Falkai P, Scherk H. Neurocognitive functions in euthymic bipolar patients. Acta Psychiatr Scand. 2009;119(5):365-74.

89. Maalouf FT, Klein C, Clark L, Sahakian BJ, Labarbara EJ, Versace A, Hassel S, Almeida JR, Phillips ML. Impaired sustained attention and executive dysfunction: bipolar disorder versus depression-specific markers of affective disorders. Neuropsychologia. 2010;48(6):1862-8.

90. Goswami U, Sharma A, Varma A, Gulrajani C, Ferrier IN, Young AH, Gallagher P, Thompson JM, Moore PB. The neurocognitive performance of drug-free and medicated euthymic bipolar patients do not differ. Acta Psychiatr Scand. 2009;120(6):456-63.

91. Roiser JP, Cannon DM, Gandhi SK, Taylor Tavares J, Erickson K, Wood S, Klaver JM, Clark L, Zarate CA Jr, Sahakian BJ, et al. Hot and cold cognition in unmedicated depressed subjects with bipolar disorder. Bipolar Disord. 2009;11(2):178-89.

92. Lopez-Jaramillo C, Lopera-Vasquez J, Gallo A, Ospina-Duque J, Bell $\checkmark$, Torrent C, Martinez-Aran A, Vieta E. Effects of recurrence on the cognitive performance of patients with bipolar I disorder: implications for relapse prevention and treatment adherence. Bipolar Disord. 2010;12(5):557-67.

93. Sheffield JM, Williams LE, Cohen N, Heckers S. Relational memory in psychotic bipolar disorder. Bipolar Disord. 2012;14(5):537-46.

94. Simonsen C, Sundet K, Vaskinn A, Birkenaes AB, Engh JA, Faerden A, Jonsdottir H, Ringen PA, Opjordsmoen S, Melle I, et al. Neurocognitive dysfunction in bipolar and schizophrenia spectrum disorders depends on history of psychosis rather than diagnostic group. Schizophr Bull. 2011;37(1):73-83.
95. Levy B, Weiss RD. Neurocognitive impairment and psychosis in bipolar I disorder during early remission from an acute episode of mood disturbance. J Clin Psychiatry. 2010;71(2):201-6.

96. Savitz J, van der Merwe L, Stein DJ, Solms M, Ramesar R. Neuropsychological status of bipolar I disorder: impact of psychosis. Br J Psychiatry. 2009;194(3):243-51.

97. Bora E, Yucel M, Pantelis C. Neurocognitive markers of psychosis in bipolar disorder: a meta-analytic study. J Affect Disord. 2010;127(1-3):1-9.

98. de Almeida Rocca CC, de Macedo-Soares MB, Gorenstein C, Tamada RS, Isller CK, Dias RS, de Almeida KM, Schwartzmann AM, Amaral JA, Lafer B. Verbal fluency dysfunction in euthymic bipolar patients: a controlled study. J Affect Disord. 2008;107(1-3):187-92.

99. Bowie CR, Best MW, Depp C, Mausbach BT, Patterson TL, Pulver AE, Harvey PD. Cognitive and functional deficits in bipolar disorder and schizophrenia as a function of the presence and history of psychosis. Bipolar Disord. 2018;20(7):604-13.

100. Savitz J, Solms M, Ramesar R. Neuropsychological dysfunction in bipolar affective disorder: a critical opinion. Bipolar Disord. 2005;7(3):216-35.

101. Sole B, Bonnin CM, Torrent C, Martinez-Aran A, Popovic D, TabaresSeisdedos R, Vieta E. Neurocognitive impairment across the bipolar spectrum. CNS Neurosci Ther. 2012;18(3):194-200.

102. Sole B, Martinez-Aran A, Torrent C, Bonnin CM, Reinares M, Popovic D, Sanchez-Moreno J, Vieta E. Are bipolar II patients cognitively impaired? A systematic review. Psychol Med. 2011;41(9):1791-803.

103. Bora E, Yucel M, Pantelis C, Berk M. Meta-analytic review of neurocognition in bipolar II disorder. Acta Psychiatr Scand. 2011;123(3):165-74.

104. Arts B, Jabben N, Krabbendam L, van Os J. A 2-year naturalistic study on cognitive functioning in bipolar disorder. Acta Psychiatr Scand. 2011;123(3):190-205.

105. Lewandowski KE, Cohen BM, Ongur D. Evolution of neuropsychological dysfunction during the course of schizophrenia and bipolar disorder. Psychol Med. 2011;41(2):225-41.

106. Szmulewicz A, Valerio MP, Martino DJ: Longitudinal analysis of cognitive performances in recent-onset and late-life Bipolar Disorder: A systematic review and meta-analysis. Bipolar Disord 2019.

107. McKay AP, Tarbuck AF, Shapleske J, McKenna PJ. Neuropsychological function in manic-depressive psychosis. Evidence for persistent deficits in patients with chronic, severe illness. Br J Psychiatry. 1995;167(1):51-7.

108. Denicoff KD, Ali SO, Mirsky AF, Smith-Jackson EE, Leverich GS, Duncan CC, Connell EG, Post RM. Relationship between prior course of illness and neuropsychological functioning in patients with bipolar disorder. J Affect Disord. 1999;56(1):67-73.

109. Jimenez-Lopez E, Sanchez-Morla EM, Lopez-Villarreal A, Aparicio Al, Martinez-Vizcaino V, Vieta E, Rodriguez-Jimenez R, Santos JL. Neurocognition and functional outcome in patients with psychotic, non-psychotic bipolar I disorder, and schizophrenia. A five-year follow-up. Eur Psychiatry. 2019;56:60-8.

110. Van Rheenen TE, Lewandowski KE, Bauer IE, Kapczinski F, Miskowiak K, Burdick KE, Balanza-Martinez V: Current understandings of the trajectory and emerging correlates of cognitive impairment in bipolar disorder: An overview of evidence. Bipolar Disord 2019.

111. Ehrminger M, Brunet-Gouet E, Cannavo AS, Aouizerate B, Cussac I, Azorin JM, Bellivier F, Bougerol T, Courtet P, Dubertret C et al: Longitudinal relationships between cognition and functioning over 2 years in euthymic patients with bipolar disorder: a cross-lagged panel model approach with the FACE-BD cohort. Br J Psychiatry 2019:1-8.

112. Ott C, Mine H, Petersen JZ, Miskowiak K. Relation between functional and cognitive impairments in remitted patients with bipolar disorder and suggestions for trials targeting cognition: an exploratory study. J Affect Disord. 2019;257:382-9.

113. Burdick KE, Endick CJ, Goldberg JF. Assessing cognitive deficits in bipolar disorder: are self-reports valid? Psychiatry Res. 2005;136(1):43-50,

114. Chan RC, Lui SS, Wang Y, Liu AC, Chui WW, Shum DH, Cheung EF. Patients with bipolar disorders share similar but attenuated prospective memory impairments with patients with schizophrenia. Psychol Med. 2013:43(8):1639-49.

115. van der Werf-Eldering MJ, Burger $\mathrm{H}$, Jabben $\mathrm{N}$, Holthausen EA, Aleman A, Nolen WA. Is the lack of association between cognitive complaints and objective cognitive functioning in patients with bipolar disorder moderated by depressive symptoms? J Affect Disord. 2011;130(1-2):306-11. 
116. Lin X, Lu D, Huang Z, Chen W, Luo X, Zhu Y. The associations between subjective and objective cognitive functioning across manic or hypomanic, depressed, and euthymic states in Chinese bipolar patients. J Affect Disord. 2019;249:73-81.

117. Miskowiak KW, Burdick KE, Martinez-Aran A, Bonnin CM, Bowie CR, Carvalho AF, Gallagher P, Lafer B, Lopez-Jaramillo C, Sumiyoshi $T$, et al. Assessing and addressing cognitive impairment in bipolar disorder: the International Society for Bipolar Disorders Targeting Cognition Task Force recommendations for clinicians. Bipolar Disord. 2018;20(3):184-94.

118. Fountoulakis KN, Grunze H, Vieta E, Young A, Yatham L, Blier P, Kasper S, Moeller HJ. The International College of Neuro-Psychopharmacology (CINP) Treatment Guidelines for Bipolar Disorder in Adults (CINPBD-2017), Part 3: The Clinical Guidelines. Int J Neuropsychopharmacol. 2017;20(2):180-95.

119. Fountoulakis KN, Yatham L, Grunze H, Vieta E, Young A, Blier P, Kasper S, Moeller HJ. The International College of Neuro-Psychopharmacology (CINP) Treatment Guidelines for Bipolar Disorder in Adults (CINPBD-2017), Part 2: Review, Grading of the Evidence, and a Precise Algorithm. Int J Neuropsychopharmacol. 2017;20(2):121-79.

120. Ghaemi SN, Gilmer WS, Dunn RT, Hanlon RE, Kemp DE, Bauer AD, Chriki L, Filkowski MM, Harvey PD. A double-blind, placebo-controlled pilot study of galantamine to improve cognitive dysfunction in minimally symptomatic bipolar disorder. J Clin Psychopharmacol. 2009;29(3):291-5.

121. Burdick KE, Braga RJ, Nnadi CU, Shaya Y, Stearns WH, Malhotra AK. Placebo-controlled adjunctive trial of pramipexole in patients with bipolar disorder: targeting cognitive dysfunction. J Clin Psychiatry. 2012;73(1):103-12.

122. Dean OM, Bush Al, Copolov DL, Kohlmann K, Jeavons S, Schapkaitz I, Anderson-Hunt M, Berk M. Effects of N-acetyl cysteine on cognitive function in bipolar disorder. Psychiatry Clin Neurosci. 2012;66(6):514-7.

123. Mclntyre RS, Soczynska JK, Woldeyohannes HO, Miranda A, Vaccarino A Macqueen G, Lewis GF, Kennedy SH. A randomized, double-blind, controlled trial evaluating the effect of intranasal insulin on neurocognitive function in euthymic patients with bipolar disorder. Bipolar Disord. 2012;14(7):697-706.

124. Watson S, Gallagher P, Porter RJ, Smith MS, Herron LJ, Bulmer S, North-East Mood Disorders Clinical Research G, Young AH, Ferrier IN. A randomized trial to examine the effect of mifepristone on neuropsychological performance and mood in patients with bipolar depression. Biol Psychiatry. 2012;72(11):943-9.

125. Yatham LN, Mackala S, Basivireddy J, Ahn S, Walji N, Hu C, Lam RW, Torres IJ. Lurasidone versus treatment as usual for cognitive impairment in euthymic patients with bipolar I disorder: a randomised, open-label, pilot study. Lancet Psychiatry. 2017;4(3):208-17.

126. Zhou Y, Zheng W, Liu W, Wang C, Zhan Y, Li H, Chen L, Li M, Ning Y. Neurocognitive effects of six ketamine infusions and the association with antidepressant response in patients with unipolar and bipolar depression. J Psychopharmacol. 2018;32(10):1118-26.

127. Kessler U, Schoeyen HK, Andreassen OA, Eide GE, Malt UF, Oedegaard KJ, Morken G, Sundet K, Vaaler AE. The effect of electroconvulsive therapy on neurocognitive function in treatment-resistant bipolar disorder depression. J Clin Psychiatry. 2014;75(11):e1306-13.

128. Yang LL, Zhao D, Kong LL, Sun YQ, Wang ZY, Gao YY, Li N, Lu L, Shi L, Wang $X Y$, et al. High-frequency repetitive transcranial magnetic stimulation (rTMS) improves neurocognitive function in bipolar disorder. $J$ Affect Disord. 2019;246:851-6.

129. Martinez-Aran A, Torrent C, Sole B, Bonnin CM, Rosa AR, SanchezMoreno J, Vieta E. Functional remediation for bipolar disorder. Clin Pract Epidemiol Ment Health. 2011;7:112-6.

130. Torrent C, Bonnin Cdel M, Martinez-Aran A, Valle J, Amann BL, Gonzalez-Pinto A, Crespo JM, Ibanez A, Garcia-Portilla MP, TabaresSeisdedos $\mathrm{R}$, et al. Efficacy of functional remediation in bipolar disorder: a multicenter randomized controlled study. Am J Psychiatry. 2013;170(8):852-9.

131. Lahera G, Benito A, Montes JM, Fernandez-Liria A, Olbert CM, Penn DL. Social cognition and interaction training (SCIT) for outpatients with bipolar disorder. J Affect Disord. 2013;146(1):132-6.

132. Sanchez-Moreno J, Bonnin C, Gonzalez-Pinto A, Amann BL, Sole B, Balanza-Martinez V, Arango C, Jimenez E, Tabares-Seisdedos R, GarciaPortilla MP, et al. Do patients with bipolar disorder and subsyndromal symptoms benefit from functional remediation? A 12-month follow-up study. Eur Neuropsychopharmacol. 2017;27(4):350-9.

133. Sole B, Bonnin CM, Mayoral M, Amann BL, Torres I, Gonzalez-Pinto A, Jimenez E, Crespo JM, Colom F, Tabares-Seisdedos R, et al. Functional remediation for patients with bipolar II disorder: improvement of functioning and subsyndromal symptoms. Eur Neuropsychopharmacol. 2015;25(2):257-64.

134. Tsapekos D, Seccomandi B, Mantingh T, Cella M, Wykes T, Young AH: Cognitive enhancement interventions for people with bipolar disorder: A systematic review of methodological quality, treatment approaches, and outcomes. Bipolar Disord 2019.

135. Bonnin CDM, Valls E, Rosa AR, Reinares M, Jimenez E, Sole B, Montejo $L$, Meseguer A, Pacchiarotti I, Colom F, et al. Functional remediation improves bipolar disorder functioning with no effects on brainderived neurotrophic factor levels. Eur Neuropsychopharmacol. 2019;29(6):701-10.

\section{Publisher's Note}

Springer Nature remains neutral with regard to jurisdictional claims in published maps and institutional affiliations.

Ready to submit your research? Choose BMC and benefit from:

- fast, convenient online submission

- thorough peer review by experienced researchers in your field

- rapid publication on acceptance

- support for research data, including large and complex data types

- gold Open Access which fosters wider collaboration and increased citations

- maximum visibility for your research: over 100M website views per year

At BMC, research is always in progress.

Learn more biomedcentral.com/submissions 